International Journal of Child, Youth and Family Studies (2014) 5(1): 47-69

\title{
IT'S TIME TO TALK ABOUT IT: UTILIZING A COMMUNITY-BASED RESEARCH APPROACH TO DEVELOP A FAMILY GUIDE FOR YOUTH SUICIDE PREVENTION
}

\section{Kim Gryglewicz, Meredith B. Elzy, Renee R. Brown, Krista Kutash, and Marc S. Karver}

\begin{abstract}
Utilizing principles from family-driven care and community-based research, community members and researchers collaborated to uncover the experiences, perceptions, and needs of families whose children had been impacted by mental illness and suicide. Using a flexible and iterative process involving in-depth qualitative interviews, four themes emerged: (a) the need for greater awareness about youth suicide; (b) the need to provide clear and direct steps to obtain help for at-risk youths; (c) the need to learn how to locate and access resources to seek help and overcome barriers to care; and (d) the importance of involving and empowering families to get involved in the design and increased utilization of treatment services and suicide prevention efforts. Further thematic content analysis revealed specific content areas that served as the foundation for the creation of a family-focused guide on youth suicide prevention. Preliminary findings with community stakeholders suggest that the family guide, It's Time to Talk About it, is a useful and motivational resource that enhances awareness on how to prevent youth suicide and how families can become more involved in treatment and advocacy efforts. This paper provides an example of how to engage and partner with community participants throughout the stages of planning, developing, implementing, and disseminating a community-based suicide prevention effort.
\end{abstract}

Keywords: youth suicide prevention, family-driven care, at-risk youth, community-based research $(\mathrm{CBR})$

Author Note: This project was funded by grant number 1U79SM058379-01 from the Substance Abuse and Mental Health Services Administration through the Garret Lee Smith Memorial Act. The views expressed in this paper do not necessarily reflect the views, opinions, or policies of CMHS, SAMHSA, or HHS; nor does mention of trade names, commercial practices, or organizations imply endorsement by the United States Government. Authors have complied with APA ethical principles in their treatment of individuals participating in the research described in this manuscript. All research activities were approved by the Institutional Review Board at the University of South Florida. Correspondence concerning this article and the Family Guide for Suicide Prevention should be addressed to Kim Gryglewicz, Department of Psychology, University of South Florida, 4202 East Fowler Avenue, PCD 4118 G, Tampa, Florida 33620. E-mail: kgryglew@mail.usf.edu. 
International Journal of Child, Youth and Family Studies (2014) 5(1): 47-69

Kim Gryglewicz, Ph.D., MSW (the corresponding author) is a Senior Research Associate at the Department of Psychology and Adjunct Faculty in the School of Social Work, University of South Florida, 4202 East Fowler Avenue, PDC 4118G, Tampa, Florida 33620, U.S.A. E-mail: kgryglew@mail.usf.edu. Dr. Gryglewicz specializes in mental health and suicide prevention community-based planning, program implementation, research, and evaluation.

Meredith Elzy, Ph.D. is an Assistant Professor at the University of South Carolina, Aiken. She received her doctorate in Clinical Psychology from the University of South Florida, 4202 East Fowler Avenue, PDC 4118G, Tampa, Florida 33620, U.S.A. E-mail: melzy@mail.usf.edu. Dr. Elzy's research focuses on the impact of emotional invalidation in the development of psychopathology.

Renee Brown is a third year doctoral student in Clinical Psychology at the University of South Florida, 4202 East Fowler Avenue, PDC 4118G, Tampa, Florida 33620, U.S.A. E-mail: rrbrown5@usf.edu. She is studying the relationships between sexual harassment and suicidality in college women. Other research interests include resilience to self-harm behaviors in survivors of trauma.

Krista Kutash, Ph.D. is Professor Emeritus in the Department of Child and Family Studies at the University of South Florida, 4202 East Fowler Avenue, Tampa, Florida 33620, U.S.A. E-mail: kutash@usf.edu. Dr. Kutash specializes in services research for children with emotional disorders and their families.

Marc S. Karver, Ph.D. is an Associate Professor in the Department of Psychology at the University of South Florida, 4202 East Fowler Avenue, PDC 4118G, Tampa, Florida 33620, U.S.A. E-mail: mkarver@usf.edu. Dr. Karver’s research interests include the assessment, management, treatment, and prevention of youth suicidality and treatment process research. 
Over the last two decades, there has been a growing movement in the United States to transform and improve mental health service delivery systems and outcomes into becoming family-focused and family-driven (Duchnowski \& Kutash, 2007; Spencer, Blau, \& Mallery, 2010). Federal legislation, policies, and grassroots efforts taken by family advocates and organizations have been largely responsible for redefining the family's role within service delivery systems, shifting the focus of care away from provider-driven practices and instead toward renewed values and beliefs that families can and should play an integral role in their children's care (New Freedom Commission on Mental Health, 2003; Spencer et al., 2010). Although excellent progress has been made in increasing family involvement in the mental health service system, similar advancements have not been made within the field of youth suicide prevention (Breton et al., 2002; McKeon, 2006). Given that family connectedness and support appear to be important protective factors in lowering the risk of adolescent depression (Van Voorhees et al., 2008) and suicidal ideation (Hall-Lande, Eisenberg, Christenson, \& Neumark-Sztainer, 2007; Kerr, Preuss, \& King, 2006), the need to engage and involve families in the design and implementation of youth suicide prevention programming is clearly warranted.

This paper describes our efforts to engage and involve community members in a countywide suicide prevention initiative to raise awareness about youth suicide. This initiative was part of a larger federally funded project known as the Florida Adolescent Suicide Awareness and Prevention (ASAP) Project, that was created to develop and implement a series of educational, training, and outreach initiatives aimed at reducing adolescent suicide morbidity and mortality rates in a densely populated county in Florida that had been affected by the growing number of youth suicide attempts and deaths by suicide (Gryglewicz et al., 2012). Due to lack of family involvement in youth suicide prevention, in particular, one of the overarching goals of the ASAP project was to enhance family participation within these initiatives.

Utilizing principles of family-driven care (Osher, Osher, \& Blau, 2008) and CBR or community-based research (Israel, Eng, Schulz, Parker, \& Becker, 1998) to guide our efforts, as community researchers from a large metropolitan university in the southeastern United States, we sought to first develop collaborative and sustainable partnerships with community members who had been impacted by suicide (i.e., family members of at-risk suicidal youth, survivors of suicide [family members who had lost a youth to suicide], and mental health professionals working with at-risk suicidal youth). By forging these partnerships, our goal was to reduce the power differential (Green \& Mercer, 2001) that can pressure participants into telling researchers what they believe the researchers want to hear. Therefore, we strove to create a non-judgmental, non-leading, and open environment for community members to genuinely share their perspectives and experiences with us. Second, by acknowledging the expertise, strengths, knowledge, and resources of community members, key principles that underpin CBR and familydriven care, and can drive system level change (Pullman, 2009), our other goal was to collectively generate new knowledge to co-develop an educational resource that met the needs and concerns of the targeted community. This paper captures the process of how we engaged and involved community members to participate in an outreach initiative to raise awareness about youth suicide prevention. Specifically, we describe the collaborative partnership that was developed between community researchers and community members, outlining recruitment strategies and steps involved in the creation and development of the family guide, It's Time to Talk About it: A Family Guide for Youth Suicide Prevention (Gryglewicz et al., 2010). 
International Journal of Child, Youth and Family Studies (2014) 5(1): 47-69

\section{Background}

Family-driven principles. In many ways, care delivered to youths without family involvement does not make much sense. Youth are embedded within families (Bronfenbrenner, 1979). It is within families that youths develop and learn their beliefs and values. It would seem that to help troubled youths to improve their lives, family involvement would be critical. Not surprisingly, research evidence suggests that family engagement and involvement within service delivery systems improve youth outcomes (Dowell \& Ogles, 2010; Karver, Handelsman, Fields, \& Bickman, 2006). Prevention programs aimed at increasing parental involvement, in particular, have shown promising results. These programs have contributed to lower prevalence rates of early-onset substance abuse, problematic behaviors, and depressive symptomatology (Connell \& Dishion, 2008; Connell, Dishion, Yasui, \& Kavanagh, 2007; Mason et al., 2007; Stormshak et al., 2011), and to improving academic outcomes (Hill \& Tyson, 2009) and child and adolescent functioning (Kutash, Duchnowski, Sumi, Rudo, \& Harris, 2002). Perhaps, the success of prevention programs provides a firm empirical foundation for involving families and a platform to begin building programs and delivery systems that are family-driven.

The vision of family-driven care is simple, yet fundamental: Families know what is best for them, what will and will not work (Osher et al., 2008). Osher and colleagues emphasize the importance of recognizing the family's role in making informed decisions about services, programs, and policies. Based on their guiding principles of family-driven care, they suggest that:

1. families and youth be given accurate and complete information to set goals and to make informed decisions;

2. families and youth coalescence together to provide support to each other as well as to utilize their knowledge and skills for system transformation;

3. families, youth, and agencies collectively embrace decision-making responsibilities that impact funding, services, treatments, and outcomes; and

4. agencies take the initiative to remove barriers to care and to provide services that are culturally competent and sensitive to the diverse and ever-changing needs of children, youth, and families.

Given that previous research has shown that lack of family involvement can be a major barrier to participation in mental health prevention, community acceptance and adoption of mental health prevention and intervention programs, and the ultimate outcomes of intervention efforts (Herman et al., 2011; Ingoldsby, 2010; Karver et al., 2006; Lee, August, Bloomquist, Mathy, \& Realmuto, 2006), this project sought to embrace the family voice by giving community members the opportunity to become collaborative partners in developing suicide prevention educational materials for parents and families.

Community-based research. Unlike conventional forms of research that are researcherdriven at all stages of the research, CBR embraces community collaboration - that is, active engagement and involvement of community members throughout most of the stages of the research process (Green, Daniel, \& Novick, 2001). CBR builds upon community members' 
strengths and resources so that such information can be respectfully generated and incorporated into action to further advance knowledge, understand and address community needs and concerns, and enhance the health and well-being of community members (Israel et al., 1998; Minkler, 2005). Similar to the principles of family-driven care, CBR is not conducted on community members, but with and for them (Flicker, Savan, McGrath, Kolenda, \& Mildenberger, 2008). The aim of community collaboration, therefore, is to gain a deeper understanding of needs and concerns of a targeted group or population, to formulate research questions and plans to address needs, and to ensure that interventions and services that are developed in response to a community need are relevant and useful to the targeted population (Israel et al.). By seeking out and developing partnerships, we qualitatively captured the lived and social experiences of community members who had been personally impacted by mental health issues and suicidality. We also collectively developed a relevant product that targeted a significant community need, the need to prevent youth suicide.

Community needs. The initial phase of the development process for the family guide began with an observation that our targeted community was lacking educational resources for family members in the area of youth suicide prevention, as well as a global process for implementing family-driven care services. Simultaneously, research efforts being conducted as part of the ASAP project were revealing some common themes: (a) families of youths at risk for suicide were expressing a need for informational resources; (b) families were frustrated with the obstacles they faced when trying to access help for their children; and (c) families often felt that they were being isolated or left out of their children's care. In many ways, we were not surprised by this, as these themes had come up in our earlier work when trying to engage and involve parents in suicide prevention trainings in a community in the southwest United States (Gunderson et al., 2009). In this prior project, focus group participants, many of whom were parents from low-income households, reported that physical barriers such as limited time, busy work schedules, and lack of transportation and affordable childcare prevented them from participating in suicide prevention trainings. Low participation rates, however, did not equate to a lack of interest in learning about youth suicide and prevention efforts. These parents still had a desire to learn about youth suicide and prevention, expressing a need for easy-to-read materials on the topic. This participant input helped point us toward the approach we took.

Additionally, a thorough literature search was conducted to gain insight into the most supported strategies for delivering information to families. Existing research supported the use of written informational strategies, such as brochures and guides, to increase knowledge (Boundouki, Humphris, \& Field, 2004; Whittingham, Ruiter, Castermans, Huiberts, \& Kok, 2008). While informational strategies have been used to develop guides for many mental health conditions among children and adolescents (Duckworth, Gruttadaro, \& Markey, 2010; National Institute of Mental Health [NIMH], 2008), a comprehensive guide written with the help of community participants and targeted specifically to the prevention of youth suicide was clearly absent. Furthermore, critics of existing resources for youth suicide prevention believed that the lack of adequate information given to family members helped to maintain stigma related to suicide (Jacksonville Community Council Inc. [JCCI], 2007).

Development of the family advisory committee. In order to advance our initial effort to engage and involve community members in outreach efforts to raise awareness about youth 
suicide prevention, a team of mental health and suicide prevention researchers and key informants, individuals who worked in non-profit mental health agencies and who had relationships with community advocates and families in the targeted community, coalesced together with community advocates and family members to form a family advisory committee. Over the course of the first year in the ASAP project, this committee met bi-monthly to brainstorm and discuss strategies to build community partnerships and engage additional parents and family members in suicide prevention efforts, as well as to highlight general needs and concerns of the targeted community.

Based on the review of the literature, previous research findings with families of at-risk youth, and initial comments shared by community stakeholders in the targeted community, the advisory committee expressed a concern around the need for the development of informational materials for community family members on youth suicide in general, with more specific information on the warning signs of suicide and strategies to use to help youths who may be at risk. These discoveries further led to the conceptualization that a printed guide specifically written for families on youth suicide prevention was not only needed and wanted in this community, but that the family voice also needed to be incorporated into the development and dissemination process. The steps outlined below describe a qualitative, flexible, iterative, and collaborative process with community members that led to the development of the family guide, starting from a basic skeleton that was derived from community feedback and scientific research about youth suicide prevention, and finishing with the finalized product.

\section{Methods}

\section{Community Participants and Procedures}

In order to further explore the community's need and desire for informational materials on youth suicide prevention, the advisory committee made a collective decision to obtain input from community members who had direct experience dealing with youths who struggled with suicidal ideation or had attempted or died by suicide. This decision was based on models of the experiential learning process, which emphasize the combination of using both current and retrospective perspectives in an effort to provide the most comprehensive and effective learning strategies (Kolb, 1984). Given that one of the goals in the ASAP project was to develop a suicide prevention resource specifically for adult family members who could come in contact with an atrisk youth, recruitment efforts focused solely on adults. As such, this process began with the recruitment of 12 parents with youths currently at risk of suicide, 18 survivors of suicide who were able to provide retrospective insight into the needs of family members who struggle to find and receive the help they need, eight mental health professionals involved in the treatment of youth at risk of suicide, and five professionals actively involved in suicide prevention advocacy efforts. All of the participants were from different families. Among survivors of suicide, six were parents who had lost a daughter or son to suicide, two were adult children who had lost a parent, three were adult siblings, and seven identified themselves as losing a family member. Participants' roles were the same in that all community members had an equal opportunity to share personal accounts and perspectives. Participants were recruited from various mental health agencies and grassroots organizations and groups in the targeted county using snowball sampling (Padgett, 2008). 
International Journal of Child, Youth and Family Studies (2014) 5(1): 47-69

Participants were sampled in an attempt to be representative of the adult population in the targeted county, which mostly reflected that of a white, working class population. Specifically, the majority of residents had identified themselves as Caucasian (62.8\%), followed by AfricanAmerican (29.8\%), and Latino(a) (7.9\%). The median household income was \$49,964. Nearly $15 \%$ lived below the poverty level. Among those over the age of 25, $87.5 \%$ had graduated from high school, 25.2\% graduated from a 4-year college (United States Census Bureau, 2011). Among study participants, 43 adults were involved in a multi-stage, multi-informant interviewing and feedback process. Of these participants, 32 (74\% of them) were female and 11 (26\%) were male. Six (14\%) participants identified as African-American, three (7\%) identified as Latino(a), and 34 (79\%) identified as Caucasian. The majority were married (60.5\%) and ranged in age from 25 to 70 years old $(M=41.50, S D=12.04)$. Educational status varied in that there was a relatively equal representation of individuals who had earned a high school diploma or GED (30.2\%), a post-secondary degree (39.6\%), and an advanced professional degree (25.6\%).

\section{Phase I: Initial Feedback and Development}

Once community members were identified and recruited by individuals from the advisory committee, members of the committee then held individual and/or group meetings to build rapport, to discuss perceived community concerns and needs, and to highlight the overall goal of the family initiative, which was to enhance familial and community participation in suicide prevention planning, implementation, and dissemination efforts. By engaging with and establishing rapport with community members, we were able to have open discussions about the needs of the community, defining shared goals and action steps to address the problem at hand. This process led to greater consensus around the need to develop educational materials on youth suicide prevention.

Following the establishment of rapport and a collaborative relationship, we then conducted in-depth qualitative interviews over the phone and in person in order to gain further insight into community members' personal experiences and perceptions about mental illness, suicide, treatment, and related fears and difficulties. We also explored content information or topics that needed to be included in a guide about youth suicide prevention. During the 60minute interview, participants confirmed their willingness to participate. Each interview was conducted by two members of the research team with the use of an interview guide to maintain the integrity of the research questions. One interviewer was the primary questioner, while the other interviewer focused on taking notes and following up with general clarification questions when necessary. Interviews were audiotaped to ensure the accuracy of the interviewers' notes and to confirm that participant perspectives had been comprehensively captured. Participants were given $\$ 20$ as tokens of appreciation for their involvement. Research protocols and questions were reviewed and approved by the University of South Florida's Institutional Review Board.

Each participant was asked a series of open-ended questions regarding content that would be appropriate for the family guide. These questions were constructed to target a participant's perspectives on five main areas of interest: 
1. existing resources available for family members with a youth at risk of suicide;

2. barriers for family members engaging in suicide prevention activities;

3. overall goals of a family guide for suicide prevention;

4. knowledge necessary for suicide prevention; and

5. any other additional information that might be relevant for family members engaging in suicide prevention activities.

\section{Phase II: Finalizing the Product}

After incorporating participant feedback to develop the initial draft of the family guide, we then conducted semi-structured telephone interviews with a subsample of participants $(n=8)$ who agreed to share additional input and to pilot test a series of questions designed to quantitatively evaluate the utility of the guide in regard to the quality and comprehensiveness of the information presented. This iterative process enabled us to determine how well the family guide met recommendations previously provided by participants. Interviews lasted 45 minutes and were conducted using the same procedures described above.

Interview questions followed a semi-structured format, alternating between a multiplechoice item and a follow-up open-ended response question to allow for flexible adaptation with participant feedback. There were three sections to this interview. For the first section, participants were asked to rate the level of importance of the primary content areas that were uncovered during the qualitative interviews. In section two, participants were asked to rate the appropriateness of the amount of information in the family guide pertaining to each of the content areas covered (see Table 1). For each rating item, participants were asked to provide additional feedback if needed. In the third and final section, participants were asked a series of individual items designed to evaluate the general utility of the family guide. Participants were asked whether they would use the family guide and recommend its use to others, and whether or not they perceived the guide as being a useful resource for themselves and other families. Participants were also asked to rate whether or not the family guide instills a sense of hope and if it helps to empower and motivate parents and families to become more engaged in their children's care and in suicide prevention initiatives.

Changes were made to the family guide to incorporate additional feedback provided by participants during the semi-structured interviews. A published version of the family guide was then distributed to all of the participants for one last review. Participants were asked to provide general feedback about the content and design. This feedback was reviewed and integrated one more time. Based on recommendations from community participants and the advisory committee, the final version of the family guide was then distributed at venues where families, youth, community mental health professionals, and suicide prevention advocates frequented, including schools, family resource centers, churches, crisis centers, mental health and substance abuse agencies, medical centers, emergency shelters, and counseling centers. Over 6,000 family guides were distributed during the initial year of circulation. 
International Journal of Child, Youth and Family Studies (2014) 5(1): 47-69

\section{Data Analysis}

Participants' recorded responses to the qualitative interview questions were first transcribed verbatim by research assistants. To start the process of developing an initial coding scheme, two members of the research team (the first and second authors) selected two transcripts to read together. Keeping in mind the five main areas of interest described above, we searched for relations, commonalities, and distinctions. Key words, phrases, or sentences emerging from the two transcripts were highlighted and coded. Next, we began to identify an initial coding scheme to sort and group the data into categories. Preliminary definitions and rules describing the coding scheme and categorization process were documented to create an audit trail for validation purposes (Lincoln \& Guba, 1985).

The remaining transcripts were coded independently by the two researchers and then compared to determine the degree of consensus in how data was coded, sorted, and categorized into the initial set of categories. If disagreements existed, the researchers re-read the transcripts, discussed the discrepancy until a consensus was reached, and if needed, additional categories and/or subcategories were refined or created. When new categories and/or subcategories emerged, all of the transcripts were reanalyzed by the two researchers to assure that key points were not lost during the process of expanding the initial set of categories. This constant comparative method (Glaser \& Strauss, 1967) was utilized in order to maintain the integrity of participant responses while simultaneously developing non-overlapping categories. Once saturation was achieved, categories and subcategories were then examined to formulate overarching themes.

To establish rigor and trustworthiness, we relied on peer examination from members of the advisory committee during the coding and thematic process. This process enhanced the quality and credibility of the data in that others outside the research team were able to crosscheck how categories and themes were being developed, thereby keeping the researchers objective in their quest to find meaning behind the data (Krefting, 1991). Testimonial validation, or member checking (Lincoln \& Guba, 1985), also provided added assurance that we accurately captured what community members had shared and deemed important to include in the family guide. This strategy was of particular importance while writing the content for the guide.

This iterative process of coding to categorizing, to redefining categories, and to searching for meaningful patterns and themes (Patton, 1990) is what led us to the final framework that outlines the main content areas of the family guide. The additional comments provided by participants in regard to the presentation of the material, including strategies and language to engage family members, were incorporated into the writing of the family guide. Throughout the entire writing process, participants and members of the advisory committee reviewed the style, language, and reading level of the family guide to ensure that the content reflected the voices of the community. Descriptive statistics were used to examine quantitative data and to corroborate qualitative findings. 
International Journal of Child, Youth and Family Studies (2014) 5(1): 47-69

\section{Results}

\section{Qualitative Interviews}

Four primary themes or domains were ascertained from the qualitative interviews with participants relative to identifying important content to be included in the family guide. These domains were labeled as the following: (a) Problem awareness, (b) Being available to youth, (c) Overcoming barriers to service utilization, and (d) Family involvement. With regard to the first three themes, the different groups of participants gave surprisingly similar responses. However, in the family involvement theme, survivors of suicide emphasized topics such as denial and stigma more frequently than parents of currently at-risk adolescents. Participant responses and thematic content from these domains are outlined below.

Problem awareness. The most prevalent topic indicated by participants was the need to raise family members' awareness that a problem with suicide risk may exist with their youth. One survivor articulated this point by stating, "parents may think that it is just a phase that they [the at-risk adolescents] are going through. It may be more than that." Another parent expressed the need to provide "clear explanations" about youth suicide, noting "there are some families out there that just don't believe that [suicide] is real and that it can happen to their child or youth." Relatedly, participants discussed the importance of educating family members with the information necessary to recognize the warning signs of adolescent suicide risk. In particular, participants emphasized that the warning signs of suicide needed to be placed in a context of "normal" adolescent development so that family members would be able to recognize and differentiate between typical adolescent development and symptoms of a youth struggling with depression, which suggests it is time to seek help. One survivor recounted:

I think one of the things that I encountered is how much of that teenage angst goes along with the normal development versus the significant mood changes that do with the more serious mental illnesses. It's hard to tell sometimes because the acting out has a lot of similarities. I wish that I had known more when I was going through that, knowing the overall warning signs that something was going on.

Participants also communicated that lack of adequate family member knowledge on mental health issues and suicidality contributed to stigma and family members' denial of the existence of a problem. Many participants expressed that these are the primary obstacles in family members getting the help they need and thus awareness about the issues of stigma and denial relating to mental health issues also needed to be raised, as one parent expressed:

A lot of people walk around with blinders on [believing] it's not going to happen to me, my kid wouldn't do that, they wouldn't do that to me...one of the biggest problems is not knowing or even ignoring the signs. Getting people to listen and know what those signs are. A lot of people have the belief if we ignore it, it will go away; or that they can handle it on their own.

Being available to youth. Some participants emphasized the importance of providing family members with clear and simple ways to directly help youth. For example, participants 
International Journal of Child, Youth and Family Studies (2014) 5(1): 47-69

commented on the importance of parents just being available to their children so that they have the opportunity to observe the warning signs. One parent of a youth who was currently seeking mental health services to address suicidal ideation commented:

The families need to have the knowledge that it is happening, it is real. A lot of family members are so caught up in what's going on in their busy day and they really need to pay close attention to what's going on in their homes. They need to have knowledge so that they can help.

Another participant, who was a survivor of suicide, gave a retrospective account of wishing she had been around her youth more often so that she could have monitored her teenager's behavior more closely. She noted: "A good message for parents to receive is if you start to pick up on things, have these cues, these gut feelings." She further alluded to the importance of "establishing rules and boundaries...to let [youth] be independent but to also have a clear understanding of the rules that say that I will monitor your activity because I think it's important, I care." Additional participants agreed that it is important to be emotionally "present" for their children, "to be around, to sit down and find out what's going on." A survivor poignantly described:

I think the parent's communication with the child is critical. It is probably one of the most important things that can assist in deterring suicide. Even communicating with friends and adults that are significant to that child. You might get nothing at all or you might just get a little bit of information. They may be looking for that opportunity.

In particular, participants felt family members could be more available to their youths if they were provided with information on ways to promote emotional resiliency, ways to effectively monitor the behavior of an at-risk youth, and strategies to help family members communicate with youth who may be at risk of suicide.

Overcoming barriers to service utilization. While some participants identified various locations in the community that might have accessible resources on where and how to seek help, such as medical offices, libraries, and schools, other participants stated they did not know how or where to access local resources. All participants were consistent in their belief that accessing services is overwhelming and that most family members are unfamiliar with the steps or processes to obtain help. One participant commented: "It's very hard, I think, to know where even to begin. If you have at least a beginning point then at least you could follow through from that part of it." Another participant stated: "I had no idea where to start. I didn't know what resources were available. Just knowing what's available out there is really important, just knowing where to turn to." In addition, participants commented that families are reluctant to seek services because of prior negative experiences with professional providers, that lack of alliance or disconnect between professional providers and family members, and/or financial constraints that limit access. One mental health professional pointed out the importance of educating families about the need to stay in treatment even if that disconnect occurs:

Sometimes when I talk to families they will say treatment is not working, it's a waste of time. Families need to be educated about what therapy is. You don't abruptly stop 
International Journal of Child, Youth and Family Studies (2014) 5(1): 47-69

treatment because they or the kids are not getting along with the therapist, or the therapist is not communicating right. You know, sometimes it doesn't always gel with an individual so maybe there's someone else on the team that might be better suited for the child or family.

Consistent with these problems, participants unanimously agreed there was a need for accessible written resources in the community and that such written resources, like the family guide, should include information about specific steps on where and how to access help and on how to work with professionals in order to overcome barriers to seeking and receiving mental health services.

Family involvement. A common theme expressed across participants was an emphasis on the importance of involving and empowering family members to get involved in suicide prevention efforts. Participants discussed how involving parents in suicide prevention could not be superficial but instead required reaching family members on an emotional level to encourage the hope and confidence needed to get involved. One survivor passionately delivered this message regarding advocacy for youth suicide prevention: "People need to get mad about it. They need to get passionate about it. People have to see that they can make a difference. [We] need to move them to become passionate about it. One child is too many."

However, only participants who were already involved in suicide prevention advocacy had suggestions for increasing participation. Participants who were not already involved in suicide prevention advocacy had little to no input on how to increase involvement. The involved participants suggested that it is difficult to get people involved unless they have been personally touched by a death from suicide. One survivor noted this while describing her role as an advocate:

Whenever I talk about teenage suicide, people are shocked. They have no idea. They just don't have a clue. So, what I have found in my experience is that people do not become advocates until they have experienced a personal loss and then you say, gosh, I wish we could have had this support before that step, before the suicide. People don't realize the severity of it. I think that society is uncomfortable and we don't like to talk about it. Probably the one thing that could make the most difference in youth suicide is the advocacy of parents.

Participants also emphasized that in order to increase personal and community-wide participation, there first needed to be a raising of awareness about the reality of youth suicide, a clarifying of the myths and facts about suicide, and an addressing of stigma relative to involvement in mental health treatment and suicide prevention. One survivor acknowledged that, "stigma does exist" and that there is a "fear of labeling a child" which may deter families from seeking help, further noting that, "you want to believe that your child is not afflicted by anything. You want the very best for your child, including emotional health. Denial is the easiest thing to do. It is the biggest barrier." A parent of an at-risk youth also expressed that one of the biggest barriers to advocacy is lack of knowledge, further acknowledging that the lack of awareness about suicide and mental health treatment is what is reinforcing feelings of denial and misconceptions that suicide only affects "other families" and is a "sign of weakness." 
International Journal of Child, Youth and Family Studies (2014) 5(1): 47-69

Fundamentally, participants wanted to know how to empower families and steps that could be helpful to engage more families to participate in advocacy efforts at state and local levels.

Overall, participants felt a written document specifically focusing on the needs of parents and families could be a useful tool to increase family involvement in suicide prevention. All participants mentioned it was critical to have information and resources, needed by a family member who knows a youth at risk of suicide, in one body of work that is easily accessible. However, they pointed out that how the information in the family guide is delivered could substantially affect its use. Suggestions mentioned by participants included omitting professional jargon, utilizing an indirect approach through language which could be relevant to someone's own child or the child of someone they know, and including parts meant specifically to instill hope and motivation.

\section{Developing the Family Guide}

In order to create the family guide, the first step was to frame the content of the guide around the categories and themes identified from the qualitative interviews described above. Thematic content analysis of these interviews identified 12 specific topics that participants believed should be in a family guide for suicide prevention. These included:

1. warning signs of suicide;

2. specific steps to getting help;

3. accessing resources in the community;

4. ways to promote emotional well-being and resiliency;

5. how to work with professionals;

6. how to get involved in suicide prevention efforts at the local level;

7. how to get involved in suicide prevention efforts at the state level;

8. ways to communicate with at-risk youths;

9. differences between normal adolescent behavior and suicidal risk factors;

10. awareness of stigma and denial;

11. tips on monitoring behavior of at-risk youths; and

12. ways to empower parents and families.

These 12 categories provided an outline for the content of the family guide. Content was then created to align with this outline.

After a careful examination of the research literature, relevant websites (National Federation of Families for Children's Mental Health, 2012; Suicide Prevention Resource Center [SPRC], 2012), and information from past research (Gunderson et al., 2009), information on suicide prevention, resiliency promotion, family empowerment, and programs that offer assistance to youths at risk of suicide and their families was synthesized and incorporated into the family guide in a practical, family-friendly manner, taking into account the input and recommendations made by community participants and members from the advisory committee. 
International Journal of Child, Youth and Family Studies (2014) 5(1): 47-69

\section{Semi-Structured Interviews}

Utility of the guide. The utility of the family guide was ascertained using the semistructured interview described previously. For the first section of the questionnaire evaluating the importance of each of the 12 content areas listed above, participants unanimously reported that information on warning signs of suicide and differences between normal adolescent behaviors and suicidal risk factors were very important $(M=5.00, S D=.00)$ (Table 1$)$. Information on ways to communicate with at-risk youth, promote emotional well-being, and empower families to become more involved in their children's care were also reported as being very important ( $M$ $=4.86, S D=.38$ ), followed by information describing the need for suicide prevention (e.g., addressing stigma and denial associated with suicide), how to access resources to get help, and ways to monitor at-risk youth behaviors $(M=4.71, S D=.49)$. For the second section of the questionnaire, the majority of participants reported that the information contained in the family guide was adequately described $(M=2.88, S D=.15)$; in other words, it was not too little or too much, but "just about right"; see Table 1 for the average rating for each content area.

In measuring the general utility of the family guide, all of the participants noted they would use the family guide and recommend its use to other families. In particular, they believed all families, not just those with at-risk youths, could benefit from reading the family guide. When asked to rate the degree to which the family guide "provides parents with hope," participants responded positively, noting that it provides a good amount or a great deal of hope $(M=4.86, S D$ $=.38$ ). The majority of participants also reported that the family guide fostered a sense of empowerment to take action and get needed assistance if they felt a youth was at risk of suicide. In fact, when asked to rate the degree to which the family guide "will motivate parents to act to get their children help," the majority of participants believed the family guide would be a motivational resource $(M=4.14, S D=.89)$. In sum, all of the participants reported that the family guide addressed a need in the community $(M=4.00, S D=.00)^{1}$ and contained information that was perceived as useful $(M=4.86, S D=.38)$.

\section{Discussion}

By utilizing principles of family-driven care and engaging in a CBR approach, we set a goal to engage and involve community members to become active participants and collaborative partners in a community-based initiative to raise greater awareness about youth suicide and suicide prevention. We achieved this goal by first listening to and learning about the various barriers, problems, and needs of families and helping professionals who cared for at-risk, suicidal youths, and then by getting input and recommendations from these participants to develop an educational resource that addressed the unique needs of families in the targeted community. We made sure that community participants understood that we, as researchers, valued their contributions - their knowledge and expertise. We "asked" instead of "telling" so that community participants would know that their opinions and perspectives mattered. The approach we engaged in involved a cyclical and iterative process that included partnership development and maintenance, problem identification, and a reciprocal transfer of knowledge and expertise, fundamental principles of CBR (Israel et al., 1998). In essence, by building a respectful and

\footnotetext{
${ }^{1}$ Based on a 4-point scale
} 
trusting partnership, community participants not only became more comfortable in sharing their personal accounts and experiences, they also acknowledged and valued their roles in becoming mutual decision-making partners in developing an educational product that they could call their own and that would be utilized by their community.

In conceptualizing and developing the family guide, community participants informed us that the overall content of the guide needed to reflect key points and strategies on how to prevent suicide among youth. Participants expressed the need to include content on the warning signs and risk factors of suicide. In particular, they wanted the family guide to differentiate between warning signs of suicide and normal teenager behavior. Adult survivors of suicide emphasized that this information is vital in preventing youth suicide. However, participants also felt that this was not enough. The majority commented that a major barrier for many families is that they either do not know or are unsure how or where to begin to get help for an at-risk suicidal youth. In addition, many participants stated that families do not know how to talk to youths or even how to begin conversations with them. This means that even if they believe a youth might be suicidal, they would not even be able to start a conversation with the youth to try to discuss the issue. Participants also commented that myths and misconceptions about suicide, mental illness, and help-seeking behaviors add to the difficulties in talking about the issue or getting the help they need for youths at risk. Limited knowledge of the warning signs of suicide and steps to take to seek help have been captured in other studies as well (Maine, Shute, \& Martin, 2001; Owens et al., 2011).

Given these barriers, participants expressed the need to have a document, like the Family Guide for Youth Suicide Prevention (Gryglewicz et al., 2010), provide clear and informative steps that families could follow on how to access and locate community resources and services when a youth is identified as being suicidal. An interesting note, however, is that despite the importance of including this type of information, participants also felt that the family guide needed to equally reflect on the processes of getting help. For instance, when we discussed including evidence to suggest that mental health treatment (Donaldson, Spirito, \& EspiritoSmythers, 2005; Wood, Trainor, Rothwell, Moore, \& Harrington, 2001) can help to reduce suicidal tendencies, participants informed us that we would first need to address issues of stigma around help-seeking behaviors. Thus, we made a conscientiousness effort to normalize this process. Additionally, participants spoke of negative experiences of family members with professional providers which is concerning given that lack of family involvement and engagement between parent and therapist can be a barrier to treatment adherence, retention, and outcomes (Garcia \& Weisz, 2002; Hawley \& Weisz, 2005; Karver et al., 2006). In response, we infused strategies and steps on how families can collaboratively work together with professionals in the community. This approach, which is based on the principles of family-driven care (Osher et al., 2008), emphasizes to family members that they have the right to be involved in their child's care, can help design service programs, and to, more importantly, find or help develop services that best meet the needs of their child and family.

Participants also believed that families needed to become more aware of the various roles they can play to help prevent suicide. They conveyed that, regardless of the type of role families assume, whether one becomes a suicide prevention advocate or a trusted adult who provides a listening ear to a youth in crisis, families can help to prevent youth suicide by just getting 
involved. In response to this input, steps on how families can get involved in suicide prevention activities and efforts at different levels were included in the family guide.

Throughout this multi-stage process of conceptualizing, planning, and developing the family guide, participants eagerly shared their stories, barriers, and struggles. For many, the process was both empowering and inspiring. Participants came to realize that their experiences could be a source of strength for others and thus they wanted to be able to do more. They took pride in knowing that they could help and direct others to learn how to prevent suicide. It was impressive to go through this process together and watch as each community member transformed into a suicide prevention advocate. In thinking about this process, we realized that we, as community researchers, not only learned from one another content relative to creating a guide on youth suicide prevention, but we also learned valuable methods on how to partner with communities to prevent suicide. Fundamentally, this partnership promoted a co-learning and empowering environment for us all (Israel et al., 1998).

\section{Limitations and Directions for Future Research}

Although one of the major strengths of this initiative was the extensive involvement of community participants, it should be noted that there were some limitations in the methodology and approach. For one, due to limitations imposed by federal funding, both time and resources prohibited the implementation of more of a community-based participatory research (CBPR) design. We acknowledge that a power imbalance existed at the start of the project, in that the project was initiated and led by an experienced group of suicide prevention researchers. However, through ongoing member checking and advisory committee consultation, we believe that we were able to greatly reduce this power differential. Similar barriers and challenges in conducting CBPR studies have been recognized (Flicker et al., 2008; Israel et al., 1998). Given that a CBPR approach can help to enrich the quality and outcomes of research (Minkler, 2005), future studies should consider utilizing this approach throughout all stages of the research process, especially among individuals who represent different races, ethnicities, sexual orientations, and socioeconomic strata. This in turn may help to capture broader cultural and community perspectives. Additional information may also be gleaned by targeting other nonfamily members who have frequent contact with youth and their families. Engaging school personnel, such as teachers, counselors, and coaches, could provide insight into school-based strategies to help youth at risk of suicide and their families. Future efforts could also capture the perspectives and experiences of at-risk suicidal youths as such information may provide a richer understanding of the youth experience and their perceptions of what it is like to talk about suicide with family members.

Constraints in time and resources also led to the recruitment of a relatively small sample, most of whom were white women. Therefore, future research should be directed at reaching a larger and more diverse sample of community members. As a beginning to this process, the family guide has been translated into Spanish in an effort to expand its utility and encourage feedback from more diverse cultural perspectives. Moreover, since creating the family guide, some family members have asked for different types of media or other ways for families to access this type of information. We are currently in the process of working with the community to address this need. 
International Journal of Child, Youth and Family Studies (2014) 5(1): 47-69

\section{Implications for Youth Suicide Prevention Programming and Research}

This article provides an example of how to engage and partner with community participants throughout the stages of planning, developing, implementing, and disseminating a community-based suicide prevention effort. While our approach is not the only way to engage and work with the community, we believe that others, especially in the field of suicide prevention, can learn from the principles we incorporated into our work.

By partnering with community members to create interventions, policy-makers and program developers have greater potential to design policies, programs, and tools that the community would be more receptive to and want to be involved with. As Ferguson (2003) notes, effective practices and policies derive from working with and obtaining feedback from community stakeholders. Failure to work with community members as equals not only marginalizes or discredits their contributions, but it also limits the scope and relevancy of prevention programs as communities are much more likely to be receptive to an effort they are involved in creating rather than one that is imposed upon them by outside sources. This is true for research as well. Engaging consumers in the research process can help to redefine traditional ways of conducting research. This process gives researchers the opportunity to design and implement studies that are relevant, practical, and feasible (Turnbull, Friesen, \& Ramirez, 1998). Community engagement, participation, and ownership are key attributes in helping to ensure that programs, as well as research, are developmentally and culturally appropriate to the target population (Bond \& Carmola Hauf, 2004). In fact, community collaboration and partnership building through mutual interest, goal setting, respect, and sharing of resources also appear to be staples for successful adoption and adaptation of prevention programs (Green et al., 2001).

By utilizing the principles of family-driven care and CBR to guide our work, we were able to capture the shared experiences and voices of the community. As a result, this enabled us to (a) identify a critical community need and gap in suicide prevention; (b) develop collaborative partnerships with community members; (c) mobilize community members to become involved in various stages of a family-driven initiative for youth suicide prevention; and (d) advance the field of suicide prevention by creating a user-friendly educational resource for families of at-risk suicidal youth.

\section{Conclusion}

It is essential for community participants to be at the forefront of prevention programs and initiatives from the very beginning. In our experience with developing the family guide, we found that the inclusion of community participants - their experiences, knowledge, wisdom, and perspectives - guided us to develop a prevention effort that was relevant to the needs of youth and families. This was evident by the extremely positive responses to the family guide that we received from the community. As the field of suicide prevention moves forward, it is important that policy-makers, program developers, and community researchers integrate principles of family-driven care and CBR into their work. It is likely that these principles will be critical to the sustainability of current and future youth suicide prevention efforts. 
International Journal of Child, Youth and Family Studies (2014) 5(1): 47-69

\section{References}

Bond, L. A., \& Carmola Hauf, A. M. (2004). Taking stock and putting stock in primary prevention: Characteristics of effective programs. The Journal of Primary Prevention, 24(3), 199-221. http://dx.doi.org/10.1023/b:jopp.0000018051.90165.65

Boundouki, G., Humphris, G., \& Field, A. (2004). Knowledge of oral cancer, distress and screening intentions: Longer term effects of a patient information leaflet. Patient Education and Counseling, 53(1), 71-77.http://dx.doi.org/10.1016/s0738-3991(03)00118-6

Breton, J. J., Boyer, R., Bilodeau, H., Raymond, S., Joubert, N., \& Nantel, M. A. (2002). Is evaluative research on youth suicide programs theory-driven? The Canadian experience. Suicide \& Life-Threatening Behavior, 32(2), 176-190. http:/dx.doi.org/10.1521/suli.32.2.176.24397

Brofenbrenner, U. (1979). The ecology of human development: Experiments by nature and design. Cambridge, MA: Harvard University Press. http://dx.doi.org/10.1016/0190-7409(80)90036-5

Connell, A. M., \& Dishion, T. J. (2008). Reducing depression among at-risk early adolescents: Three-year effects of a family centered intervention embedded within schools. Journal of Family Psychology, 22(3), 574-585. http://dx.doi.org/10.1037/0893-3200.22.3.574

Connell, A. M., Dishion, T. J., Yasui, M., \& Kavanagh, K. (2007). An adaptive approach to family intervention: Linking engagement in family-centered intervention to reductions in adolescent problem behavior. Journal of Consulting and Clinical Psychology, 75(4), 568-579. http://dx.doi.org/10.1037/0022-006x.75.4.568

Donaldson, D., Spirito, A., \& Espirito-Smythers, C. (2005). Treatment for adolescents following a suicide attempt: Results of a pilot study. Journal of the American Academy of Child and Adolescent Psychiatry, 44(2), 113-120. http://dx.doi.org/10.1097/00004583-200502000-00003

Dowell, K. A., \& Ogles, B. M. (2010). The effects of parent participation on child psychotherapy outcome: A meta-analytic review. Journal of Clinical Child and Adolescent Psychology, 39(2), 151-162. http://dx.doi.org/10.1080/15374410903532585

Duchnowski, A. J., \& Kutash, K. (2007). Family-driven care. Tampa, FL: University of South Florida, The Louis de la Parte Florida Mental Health Institute, Department of Child \& Family Studies.

Duckworth, K., Gruttadaro, D., \& Markey, D. (2010). What families need to know about adolescent depression (2nd ed.). [Brochure]. Arlington, VA: The National Alliance on Mental Illness.

Ferguson, H. (2003). Outline of a critical best practice perspective on social work and social care. British Journal of Social Work, 33(8), 1005-1024. http://dx.doi.org/10.1093/bjsw/33.8.1005 
International Journal of Child, Youth and Family Studies (2014) 5(1): 47-69

Flicker, S., Savan, B., McGrath, M., Kolenda, B., \& Mildenberger, M. (2008). "If you could change one thing..." What community-based researchers wish they could have done differently. Community Development Journal, 43(2), 239-253. http://dx.doi.org/10.1093/cdj/bsm009

Garcia, J. A., \& Weisz, J. R. (2002). When youth mental health care stops: Therapeutic relationship problems and other reasons for ending youth outpatient treatment. Journal of Consulting and Clinical Psychology, 70(2), 439-443. http://dx.doi.org/10.1037//0022-006x.70.2.439

Glaser, B. G., \& Strauss, A. L. (1967). The discovery of grounded theory: Strategies for qualitative research. Chicago: Aldine Publishing Company.

Green, L. W., \& Mercer, S. L. (2001). Can public health researchers and agencies reconcile the push from funding bodies and the pull from communities. American Journal of Public Health, 91(12), 1926-1929. http://dx.doi.org/10.2105/ajph.91.12.1926

Green, L., Daniel, M., \& Novick, L. (2001). Partnerships and coalitions for community-based research. Public Health Reports, 116(Suppl. 1), 20-31. http://dx.doi.org/10.1093/phr/116.s1.20

Gryglewicz, K., Brown, R., Elzy, M., Labouliere, C., Dean, M., Chen, J., ... \& Karver, M. (2012). Florida adolescent suicide awareness and prevention project. Washington, DC: Substance Abuse and Mental Health Service Administration.

Gryglewicz, K., Ojeda, D., Elzy, M., Brown, R., Kutash, K., Karver, M., \& the Florida ASAP Suicide Prevention Team. (2010). It's time to talk about it: A family guide for youth suicide prevention efforts in Duval County. Tampa, FL: University of South Florida.

Gunderson, S., Labouliere, C., Totura, C., Kutash, K., Tarquini, S., Caporino, N., ... \& Karver, M. (2009). Decreasing adolescent suicidality through a multiple component suicide prevention program: Linking adolescents at risk to mental health services. Washington, DC: Substance Abuse and Mental Health Service Administration.

Hall-Lande, J. A., Eisenberg, M. E., Christenson, S. L., \& Neumark-Sztainer, D. (2007). Social isolation, psychological health, and protective factors in adolescence. Adolescence, 42(166), 265-286.

Hawley, K. M., \& Weisz, J. R. (2005). Youth versus parent therapeutic alliance in usual clinical care: Distinctive associations with engagement, satisfaction and treatment outcome. Journal of Clinical Child \& Adolescent Psychology, 34(1), 117-128. http://dx.doi.org/10.1207/s15374424jccp3401_11

Herman, K. C., Borden, L. A., Hsu, C., Schultz, T. R., Carney, M. S., Brooks, C. M., \& Reinke, W. M. (2011). Enhancing family engagement in interventions for mental health problems in youth. Residential Treatment for Children \& Youth, 28(2), 102-119. http://dx.doi.org/10.1080/0886571x.2011.569434

Hill, N. E., \& Tyson, D. F. (2009). Parental involvement in middle school: A meta-analytic assessment of the strategies that promote achievement. Developmental Psychology, 45(3), 740-763. http://dx.doi.org/10.1037/a0015362 
International Journal of Child, Youth and Family Studies (2014) 5(1): 47-69

Ingoldsby, E. M. (2010). Review of interventions to improve family engagement and retention in parent and child mental health programs. Journal of Child and Family Studies, 19(5), 629-645. doi: 10.1007/s10826-009-9350-2 http:/dx.doi.org/10.1007/s10826-009-9350-2

Israel, B. A., Eng, E., Schulz, A. J., Parker, E. A., \& Becker, A. B. (1998). Review of community-based research: Assessing partnerships approaches to improve public health. Annual Review of Public Health, 19(1), 173-202. http://dx.doi.org/10.1146/annurev.publhealth.19.1.173

Jacksonville Community Council Inc. (JCCI). (2007, Summer). Youth suicide: Hidden crisis. Jacksonville, FL: JCCI Forward.

Karver, M. S., Handelsman, J., Fields, S., \& Bickman, L. (2006). Meta-analysis of therapeutic relationship variables in youth and family therapy: The evidence for different relationship variables in the child and adolescent treatment outcome literature. Clinical Psychology Review, 26(1), 50-65. http://dx.doi.org/10.1016/j.cpr.2005.09.001

Kerr, D. C. R., Preuss, L. J., \& King, C. A. (2006). Suicidal adolescents’ social support from family and peers: Gender-specific associations with psychopathology. Journal of Abnormal Child Psychology, 34(1), 103-114. http://dx.doi.org/10.1007/s10802-005-9005-8

Kolb, D. A. (1984). Experiential learning experience as the source of learning and development. Englewood Cliffs, NJ: Prentice Hall.

Krefting, L. (1991). Rigor in qualitative research: The assessment of trustworthiness. American Occupational Therapy, 45(3), 214-222. http://dx.doi.org/10.5014/ajot.45.3.214

Kutash, K., Duchnowski, A. J., Sumi, W. C., Rudo, Z., \& Harris, K. M. (2002). A school, family, and community collaborative program for children who have emotional disturbances. Journal of Emotional and Behavioral Disorders, 10(2), 99-107. http://dx.doi.org/10.1177/10634266020100020401

Lee, S. S., August, G. J., Bloomquist, M. L., Mathy, R., \& Realmuto, G. M. (2006). Implementing an evidence-based preventive intervention in neighborhood family centers: Examination of perceived barriers to program participation. The Journal of Primary Prevention, 27(6), 573-597. http://dx.doi.org/10.1007/s10935-006-0060-x

Lincoln, Y. S., \& Guba, E. G. (1985). Naturalistic inquiry. Beverly Hills, CA: Sage.

Maine, S., Shute, R., \& Martin, G. (2001). Educating parents about youth suicide: Knowledge, response to suicidal statements, attitudes, and intention to help. Suicide and LifeThreatening Behavior, 31(3), 320-332. http://x.doi.org/10.1521/suli.31.3.320.24248

Mason, W. A., Kosterman, R., Hawkins, J. D., Haggerty, K. P., Spoth, R. L., \& Redmond, C. (2007). Influence of a family-focused substance use preventive intervention on growth in adolescent depressive symptoms. Journal of Research on Adolescence, 17(3), 541-564. http://dx.doi.org/10.1111/j.1532-7795.2007.00534.x 
International Journal of Child, Youth and Family Studies (2014) 5(1): 47-69

McKeon, R. (2006, December). Engaging families. Presentation given at the Garrett Lee Smith State/Tribal Suicide Prevention Meeting in North Bethesda, MD.

Minkler, M. (2005). Community-based research partnerships: Challenges and opportunities. Journal of Urban Health of the New York Academy of Medicine, 82(2 Suppl 2), ii3-1112. http://dx.doi.org/10.1093/jurban/jti034

National Federation of Families for Children’s Mental Health. (2012). In Resources. Rockville, MD: Author. Retrieved from http://ffcmh.org/

National Institute of Mental Health [NIMH]. (2008). Bipolar disorder in children and teens: A parent's guide [Brochure]. Bethesda, MD: National Institutes of Health.

New Freedom Commission on Mental Health. (2003). Achieving the promise: Transforming mental health care in America. Final Report (DHHS Pub. No. SMA-03-3832). Rockville, MD: U.S. Department of Health and Human Services. http://dx.doi.org/10.1037/e513572010-001

Osher, T. W., Osher, D. M., \& Blau, G. (2008). Families matter. In T. Gullotta \& G. Blau (Eds.), Family influences on childhood behavior and development: Evidence-based prevention and treatment approaches (pp. 39-61). New York: Routledge.

Owens, C., Owen, G., Belam, J., Lloyd, K., Rapport, F., Donovan, J., \& Lambert, H. (2011, October). Recognising and responding to suicidal crisis within family and social networks: qualitative study. British Medical Journal, 343. doi: 10.1136/bmj.d5801 http://dx.doi.org/10.1136/bmj.d5801

Padgett, D. K. (2008). Qualitative methods in social work research (2nd ed.). Thousand Oaks, CA: Sage Publications, Inc.

Patton, M. Q. (1990). Qualitative evaluation and research methods (2nd ed.). Newbury Park, CA: Sage Publications, Inc.

Pullman, M. D. (2009). Participatory research in systems of care for children's mental health. American Journal of Community Psychology, 44, 43-53. http://dx.doi.org/10.1007/s10464-009-9245-9

Spencer, S. A., Blau, G. M., \& Mallery, C. J. (2010). Family-driven care in America: More than a good idea. Journal of the Canadian Academy of Child and Adolescent Psychiatry, 19(3), 176-181.

Stormshak, E. A., Connell, A. M., Véronneau, M. H., Myers, M. W., Dishion, T. J., Kavanagh, K., \& Caruthers, A. S. (2011). An ecological approach to promoting early adolescent mental health and social adaption: Family-centered intervention in public middle schools. Child Development, 82(1), 209-225. http://dx.doi.org/10.1111/j.1467-8624.2010.01551.x

Suicide Prevention Resource Center [SPRC]. (2012). In Library and resources. Retrieved from http://www.sprc.org/ 
International Journal of Child, Youth and Family Studies (2014) 5(1): 47-69

Turnbull, A. P., Friesen, B. J., \& Ramirez, C. (1998). Participatory action research as a model for conducting family research. Research and Practice for Persons with Severe Disabilities, 23(3), 178-188. http://dx.doi.org/10.2511/rpsd.23.3.178

United States Census Bureau. (2011). State and county quick facts. Retrieved April 1, 2013, from http://quickfacts.census.gov

Van Voorhees, B. W., Paunesku, D., Kuwabara, S. A., Basu, A., Gollan, J., Hankin, B. L., ... \& Reinecke, M. (2008). Protective and vulnerability factors predicting new-onset depressive episode in a representative of U.S. adolescents. Journal of Adolescent Health, 42(6), 605-616. http://dx.doi.org/10.1016/j.jadohealth.2007.11.135

Whittingham, J. R. D., Ruiter, R. A. C., Casterman, D., Huiberts, A., \& Kok, G. (2008). Designing effective health education materials: Experimental pre-testing of a theory based brochure to increase knowledge. Health Education Research, 23(3), 414-426. http://dx.doi.org/10.1093/her/cym018

Wood, A., Trainor, G., Rothwell, J., Moore, A., \& Harrington, R. (2001). Randomized trial of group therapy for repeated deliberate self-harm in adolescents. Journal of American Academy of Child and Adolescent Psychiatry, 41(11), 1246-1253.

http://dx.doi.org/10.1097/00004583-200111000-00003 
International Journal of Child, Youth and Family Studies (2014) 5(1): 47-69

Table 1. 12 Primary Content Areas Included in the Family Guide

\begin{tabular}{|c|c|c|c|c|}
\hline \multicolumn{3}{|c|}{ Level of Importance of Content ${ }^{(1)}$} & \multicolumn{2}{|c|}{$\begin{array}{c}\text { Adequacy of Content } \\
\text { Description }^{(2)}\end{array}$} \\
\hline & $M$ & $S D$ & $M$ & $S D$ \\
\hline Warning Signs of Suicide & 5.00 & .00 & 2.86 & .38 \\
\hline Adolescent Behaviors vs. Risk Factors & 5.00 & .00 & 2.86 & .38 \\
\hline Promote Emotional Well-being & 4.86 & .38 & 2.71 & .49 \\
\hline Communicate with At-Risk Youth & 4.86 & .38 & 3.00 & .00 \\
\hline Empower Parents/Families & 4.86 & .38 & 3.00 & .00 \\
\hline Assessing Resources & 4.71 & .49 & 2.86 & .38 \\
\hline Awareness of Stigma and Denial & 4.71 & .49 & 2.83 & .41 \\
\hline Monitoring Behavior of At-Risk Youth & 4.71 & .49 & 2.71 & .49 \\
\hline Steps to Get Help & 4.57 & .53 & 3.00 & .58 \\
\hline Work with Professionals in the Community & 4.57 & .53 & 2.86 & .38 \\
\hline Involved in Suicide Prevention-Local & 4.43 & .53 & 3.00 & .00 \\
\hline Involved in Suicide Prevention-State & 3.71 & .76 & 2.86 & .38 \\
\hline
\end{tabular}

Note. ${ }^{1}$ Range is from 1 (not at all important) to 5 (very important). ${ }^{2}$ Adequacy of content: Scores ranged from 1 ("not enough information") to 5 ("too much information"). A score of 3 is indicative of content areas containing "just right information.” 